\title{
Extraordinary Educative Environmental Events
}

\author{
Ming Kwan ${ }^{1}$, Anthony Kong ${ }^{2} \&$ David Liu ${ }^{3}$ \\ ${ }^{1}$ Faculty of Hospitality and Tourism Management, Macau University of Science and Technology, Avenida Wai \\ Long, Taipa, Macau, China \\ ${ }^{2}$ Department of Communication Design and Digital Media at Hong Kong Design Institute, Hong Kong, China \\ ${ }^{3}$ Faculty of Hospitality and Tourism Management, Macau University of Science and Technology, Avenida Wai \\ Long, Taipa, Macau, China \\ Correspondence: Ming Kwan, Faculty of Hospitality and Tourism Management, Macau University of Science and \\ Technology, Avenida Wai Long, Taipa, Macau. E-mail: mwkwan@must.edu.mo
}

$\begin{array}{ll}\text { Received: January 15, } 2019 & \text { Accepted: February 8, } 2019 \quad \text { Online Published: March 24, } 2019 \\ \text { doi:10.5539/jms.v9n1p101 } & \text { URL: https://doi.org/10.5539/jms.v9n1p101 }\end{array}$

\begin{abstract}
Using educative environmental protection events such as "Environmental Protection Pioneer Campaign", "Rewarding Recycling Campaign", "Green Efforts Give Great Rewards Event", "Environmental Protection Workshop", "Environmental Campaign Day", "Environmental Protection Carnival" and "Second-hand Bazaar" held in Park Island, Hong Kong, as a case study, the purpose is exploring how educative environmental protection events contribute to demonstrate environmentally friendly property management and raise the environmental protection awareness and encourage residents' involvement to live green.
\end{abstract}

Design/Methodology/Approach-This paper identifies environmental protection events as an effective strategy to raise environmental awareness for all of the estate residents. The objectives of environmental protection events aimat showing the importance of community involvement, demonstrating educative environmentally friendly property management and encourage residents to live green. Authors conducted twenty-five in-depth semi-structured interviews with participants so as to fully understand the contributions made by the events.

Findings-Educative environmental protection events were perceived by all of the study participants as effective and educative events, which raised environmental awareness, upheld moral obligation to engage in environmental protection, and induced greater pro-environmental behavior to sustainability. Based on the results, the framework of $10 \mathrm{Cs}$ is revealed which contributes to environmentally friendly environment for the next generation. These contributions are:

1) Circulating surplus materials to the needy

2) Choosing public transportation

3) Committing to green education

4) Cultivating pro-environmental behavior

5) Caring for sustainable development

6) Cutting Carbon lifestyle

7) Coordinating efforts to reduce, reuse, and recycle

8) Consuming less electricity

9) Concerning ocean creatures protection

10) Ceasing ozone depleting chemicals products

Practical implications-Based on the insights gained from participants, the 10 Cs contributions are made by educative environmental protection events for nurturing moral obligation to demonstrate environmentally friendly property management and raise the environmental protection awareness and encourage residents' involvement to live green. Participants should take part in all environmental-protection measures daily. The Estate Management Company and government should deepen cooperation in environmental protection, intensify ecological preservation and build a green living environment. 
Originality/value-This paper urges for the importance of all residents, all estate management companies and government to engage in environmental protection for sustainable development. The aim of such an episode is to arouse all stakeholders to participate in environmental protection actively and attentively for green environment.

Keywords: environmental protection event, green living, estate management

\section{Introduction}

Environmental protection and conservation are paramount because when we protect the environment, we are not protecting some distinct, distant entities but ourselves. As global warming begins to alert the awareness of the need for greater environmental conservation, energy efficiency, and better places to live and work become more prevalent. Similarly, the demand for green buildings and communities is expected to increase as well, for the reason that people today pay more attention to the healthiness and sustainability of the existing environment. Therefore, ethics of conservation become the norm which is the necessary staple in any sustainable human endeavor (Maser, Beaton, \& Smith, 1998). Nowadays, residents focus on development to become more energy efficient and ecologically friendly. Consequently, sustainability has become a touchstone for many of the business sectors (William, 2008). Nevertheless, it will bring increasing demand on energy supply; an increased burden on solid waste management, the pollution of water and air has caused negative environmental effects. Owing to these effects, substantial uncertainty exists regarding the long-term implications of such negative environmental impacts, in particular, those relating to global climate change. This increasingly calls for environmental protection for all. With the continuous growth of the population along with the convergence of rising energy costs, climate change and other pressing environmental issues, all residents, management companies and governments should take the responsibilities for environmental protection. The impacts of climate change and the efforts to combat climate change touch on every part of our lives. The issue of climate change can only be sufficiently addressed with strong support from the government, the estate management companies and residents to engage in our dailylives.

\subsection{Background of Environmental Protection Events}

The setting for the present study was educative environmental protection events held in Park Island, Hong Kong. A series of effective and educative environmental events for all ages of residents including both adults and kids such as "Environmental Protection Pioneer Campaign", "Rewarding Recycling Campaign", "Green Efforts Give Great Rewards Event", "Environmental Protection Workshop", "Environmental Campaign Day", Environmental Protection Carnival" and "Second-hand Bazaar" have been held. The meaningful, interactive and inspiring activities have been organized for spreading environmentally friendly awareness. It nurtures the awareness of environmental preservation and sustainable development for all kinds of residents.

\subsection{Park Island Background}

Park Island, named as "the leisure vacation island", is a private residential area situated in Ma Wan, which is located in the north-eastern part of Ma Wan. Park Island consists of over 5,000 residential units with 35 blocks and 4 large clubhouses covering an area of over 126,000 sq.m (Chan, 2012). In Park Island, over 40,000 sq.m are covered with greenery with gardens and mini farms, taking up nearly $40 \%$ of the site area. Since vehicle restrictions are set in Ma Wan to limit the emissions, the project by and large is described as a "pollution-free green city" which promotes one-stop green building and management (Chan, 2012). It is regarded as the first and largest eco-friendly residential area which contains a large green space since planning (Chan, 2012). The management is dedicated to implementing and promoting environmental protection concepts. Green concepts have applied in property planning, design, resources purchasing, architectural work, gardening, daily management operation and management as well as clubhouses activities and events management. Both of the community and management of Park Island are striving to conserve and cherish the natural environment. The community keenly supports sustainable development, wishing people in the future generation would be able to enjoy the natural resources on earth.

\section{Literature Review}

\subsection{Sustainable Development}

Over the years, concerns related to the environment have progressively escalated (Laroche et al., 2001). Sustainable development refers to a series of processes and practices, involving action, and focusing on the improvement of human life (WCED, 1987; Blewitt, 2008; UNSGHLPS, 2012). The analogies between sustainability and sustainable development advance towards an interrelationship understanding of a single system composed of human and environmental activities. Such understanding has a dual purpose: to satisfy human's needs and to support life-sustaining systems (Lambin, 2005; Brinsmead \& Hooker, 2011). Thus, 
sustainability encompasses systems and sustainable development looks towards human needs and their well-being. Human beings are not independent and isolated; they are part of a complex web of natural phenomena inserted in a single global system, which Moldan et al. (2012) calls a myriad of relationships and interdependencies. Sustainable development is the key to achieve sustainability, which is considered the final long-term goal (Hove, 2004). Sustainability consists of a goal or ultimate objective defined through scientific criteria, which measures and tracks the results generated by the use of sustainable development strategies. In order to achieve the sustainability of a given global system - to raise the level of sustainability quality - it is necessary to use the sustainable development process (Prugh \& Assadourian, 2003; Sartori et al., 2014; Stiglitz, Sen, \& Fitoussi, 2009). Sustainability originally was used to describe development and resource consumption that can meet human's present needs while preserving the ability of the environment in sustaining people at present and in future. It involves considering environmental, economic, and social objectives when developing and implementing public policies and programs. It also involves considering the needs of the present as well as the needs of future generations. In other words, sustainable development rests on the harmony between the needs of stakeholders. Instead of being viewed as a destination, sustainable development is an ongoing process whereby behavior is adjusted in the social and economic development and improvement which emphasizes the qualitative improvement in people's well-being. In other words, the concept suggests the community continues to improve the quality of life of its inhabitants (Brandon, 2011). This long-term planning objective of a social-environmental system in balance calls for cooperative functioning among government, institutions, community groups as well as individuals; and the concept is continuously building up from the bottom up through community initiatives. For a business to operate towards sustainability, it should start with the belief that it is part of a larger system in business ecology and extends the willingness to examine the larger socio-economic system and how we impact it at the individual, community and organizational level, and eventually at the planetary level (Laing \& Frost, 2010). Hence, green value propositions will include benefits to the physical environment of buildings and facilities, benefits to the community, and improvements to the global environment (Swarbrooke, 1999). It is beneficial to everyone for all businesses, all industry to make environmental sustainability as a management competency and an aspect of organizational excellence (Ahmad et al., 2013). In fact, creating a green culture requires reinforcing people's positive behavior (Ahmad et al., 2013). The environmental behavior that changes the availability of materials or energy from the environment or alters the structure and dynamics of ecosystems or the biosphere in environmentally responsible way (Stern, 2000).

\subsection{Event}

The term event is used for describing different activities designed for different purposes. It can be a public or private, commercial or charitable, celebratory or commemorative events which bring people together to share an experience and produce a measurable outcome (Eckerstein, 2002). According to Berridge (2007), events are a unique moment in time and aside from everyday occurrences. It is an activity that gathers the target group in time and room, a meeting where a message is communicated and happening is created (Silvers, 2004). The event is all about people coming together to create, operate, and participate in an experience (Eckerstein, 2002). The aims of environmental protection events were to increase environmental awareness for the community. The objectives of environmental protection events were showing the importance of community involvement, demonstrating environmentally friendly property management andraising the environmental protection awareness for residents to live green.

\subsection{Community Involvement}

Residents' involvement to live green should be a norm. We need to change their ways, their behaviors and their values to care about environmental protection and sustainability must become the social norm. Along with the term community, it is said that public participation is considered the centerpiece of the democratic process (Green \& Haines, 2008), which is very essential in community development. In other words, the development of a community requires the involvement and proactive participation of the local community in identifying the strategies they wish to use to improve their quality of life (Green \& Haines, 2008). In modern era, much of the policy depends on the knowledge and commitment of the people in approaching the objective of sustainable development. Since local community usually has much better knowledge about the assets and needs of the community, the development project which is supported by the local community is more likely to be successful. In response to this, it is important to accomplish a high standard of education coupled with a willingness to make sacrifices at present in order to allow future generations to have choices in their own futures, equal to what we enjoy at present (Brandon, 2011). 


\section{Methodology and Research Methods}

Research on educative environmental events in estate management contributions has used deductive processes, testing a plethora of hypotheses and pre-determined theories. Green promotion event researchers have typically approached the problem from a positivist perspective, utilizing quantitative research techniques like surveys and questionnaires, and processing data with the help of statistical data analysis tools. While mostly deductive in nature, such research tools tend to measure a set of predetermined hypotheses, searching for answers to the "what" questions and not adding for any additional factors to describe the researcher's process of reasoning (Yin, 1994). Participants in the events context have been shown to demonstrate a multitude of contributions and it is very likely that their attitudes, behaviors, perceptions and experiences of the green promotion event differ. Owing to explore more on emotional aspect, that is not possible to achieve simply by analyzing quantitative data, a qualitative research approach has been used as a more suitable research strategy. Qualitative research is regarded to be "concerned with understanding things rather than with measuring them" (Gordon \& Langmaid, 1988, p. 2), whereby the "subjectivity and the authenticity of human experience" (Silverman, 2010, p. 138) enable the researcher to gain an insight into the different feelings, meanings, perceptions, and attitudes of research subjects (Holloway et al., 2010; Veal, 2006).

The setting for the present study was educative environmental protection events held in Park Island, Hong Kong. A series of educative environmental events have been organized regularly, such as "Environmental Protection Pioneer Campaign", "Rewarding Recycling Campaign", "Green Efforts Give Great Rewards Event", "Environmental Protection Workshop", "Environmental Campaign Day", "Environmental Protection Carnival" and "Second-hand Bazaar" to advocate the environmentally friendly awareness for the Park Island residents. All these events have nurtured the awareness of environmental preservation and sustainable development for all residents. The objectives of educative environmental protection events are showing the importance of community involvement, demonstrating environmentally friendly property management and nurturing participants' moral obligation to engage in pro-environmental protection behaviors.

Park Island was selected in this study because it was the first largest eco-friendly residential area in Hong Kong. The management of Park Island is dedicated, devoted and determined towards environmental protection and promotion which have produced significant results such as being named the most energy-efficient residential estate by Friends of the Earth. The participants were the residents in Park Island community. The sample group comprised fifteen female and ten male respondents, all aged 21-60. Their education levels were secondary school (2), undergraduate (8) and postgraduate (15). They actively participate in those environmental events in Park Island. They show support to those environmentally friendly measures accordingly.

Data collection took place in the estate. The researcher undertook face to face in-depth semi-structured interviews and the duration is 40 minutes at the nearest restaurant. Participants' written consent forms were received and they understood the purpose and information of the study. Research questions and topics were designed to elicit responses about each participant's attitudes, feelings, perceptions and pro-environmental protection behaviors after attending environmental protection events, exploring general themes proposed by the environmental behavior and personal moral obligation literature. Additional prompts and questions were added to search their feelings, perceptions and attitudes after environmental protection events, in order to identify any specific incidents that may have contributed to a participant's pro-environmental behavior and personal moral obligation to engage in environmental protection. The interviews were digitally recorded and summaries were written up. Responses were analyzed using manual coding, scanning the recordings and flagging emergent themes and common views (Veal, 2006). Lastly, the results were summed up into similar conceptual categories related to prevalent themes.

\section{Findings and Discussion}

The success of environmental protection hinges on community involvement. A series of environmental events has been organized regularly in Park Island, Hong Kong, such as "Environmental Protection Pioneer Campaign", "Rewarding Recycling Campaign", "Green Efforts Give Great Rewards Event", "Environmental Protection Workshop", "Environmental Campaign Day", and "Environmental Protection Carnival" and "Second-hand Bazaar" have been held. The tailored-made meaningful and inspiring activities were launched for all ages of residents. It nurtures the awareness of environmental preservation and sustainable development for the next generation. The objectives of environmental protection events are to demonstrate environmentally friendly property management and raise the environmental protection awareness and induce greater community involvement to live green. Motivating the community to engage voluntarily is the key to success. Small steps and large collection can make a better world for all living creatures. Through sustainability by reducing greenhouse 
gas emissions, reducing waste products, increasing recycling, etc. Both small steps and large collective actions have showed how such efforts can make a big impact to the community and a better world. It is critical to motivate the community to take an active role in responding to environmentally friendly measures. Environmental protection events were held as to educate and promote ethical behaviors toward energy-saving and the environment-protection while creating memorable and meaningful event experiences.

The results of in-depth interviews revealed inspiring insights from participants' perspectives regarding the experiences and benefit contributions of environmental protection events which derived the values, attitudes, feelings, intrinsic and extrinsic motivations from participants through engaging various environmental protection actions to achieve the perceived outcome of sustainability and a green globe. Based on the results, environmental protection events were perceived by all of the study participants as a fun, educational, influential, informative, interactive and meaningful events. They inspired participants to embrace positive environmental attitudes and engage in pro-environmental behaviors in their daily lives. It raised environmental awareness, upheld moral obligation to engage in environmental protection, and induced greater pro-environmental behavior for sustainability. Based on the insights gained from event participants, lots of contributions are contributed by educative environmental protection events for nurturing residents to commit to environmental protection, and inducing greater pro-environmental behavior for future development. These contributions of 10Cs which are circulating surplus materials to the needy, choosing public transportation, committing of green education, cultivating pro-environmental behavior, caring for sustainable development, cutting carbon lifestyle, coordinating effort to reduce, reuse, recycle, consuming less electricity, concerning ocean creatures protection and ceasing ozone depleting chemicals products.

\subsection{Circulating Surplus Materials to Others}

Management encourages the community to reduce waste at source by donating usable resources to the charities through "Environmental Protection Pioneer Campaign", "Rewarding Recycling Campaign", "Green Efforts Give Great Rewards Event", "Environmental Protection Workshop", "Environmental Campaign Day", Environmental Protection Carnival" and "Second-hand Bazaar". It helps to spread the message of fully cherishing and utilizing materials and adopting a green lifestyle. It raises public awareness of the importance of waste reduction and to encourage the public to make good use of resources, making the world a greener place to live. The excerpts below show the importance of waste reduction by circulating surplus materials to others.

"We get involved with the management efforts to bring people together and to donate surplus materials to the needy via charity such as the Salvation Army in Green Day Event and Environmental Protection Carnival".

"Through Second-hand Bazaar, residents can sell unwanted or surplus materials at lower prices to people who really need those materials. It encourages residents to reduce solid waste and to encourage the transfer of materials".

\subsection{Choosing Public Transportation}

Park Island in Ma Wan, located between Lantau Island and Tsing Yi Island, is a restricted zone and traffic control has been adopted for 24 hours every day. People must use mass transport such as the specific eco-friendly shuttle bus or ferry to visit the Island. These buses are environmentally friendly, in the sense that they use either batteries or natural gas as fuels, which are far more eco-friendly than using petrol gas. Vehicles such as private cars or coaches without special permit issued by the Transport Department are not allowed to access the island. This can help to maintain the air quality in the island and uphold the principle of maintaining an environmentally friendly community. The excerpts below show the importance of using public transporation.

"I prefer to take shuttle bus that can save gasoline each year".

"Public transportation can carry large numbers of passengers than individual automobiles, that casuse less air polluction".

\subsection{Committing of Green Education}

Environmental Protection Pioneer Campaign" is aimed at nurturing the next generation to be responsible to become environmentally friendly. Assuring that all children experience safe, stable and green environments is an important goal for public health and education purposes. Another event called "Green Day Event" was aimed at raising environmental awareness for the residents. The objectives of environmental protection events are showing the importance of community involvement, demonstrating environmentally friendly property management and nurturing participants' moral obligation to engage in pro-environmental protection behaviors. 
Meanwhile, the participants provided used paper, plastics, compact discs, bicycles, clothing, and electric appliances to redeem points for useful household products.

"Owing to the greener environmental for next gernations, all the stakeholders in the community should take part to adopt a low carbon lifestyle and pay attention to sustainability".

\subsection{Cultivating Pro-Environmental Behavior}

"Environmental Protection Carnival" and "Second-hand Bazaar" have been organized every year, providing residents the platforms to sell their second-hand goods. In addition, environmental protection organizations would also be invited to join the carnival to promote green messages to the residents. Reinforcement of environmental protection measures would result in actual rewards. This further reinforces residents' motivation to play a part in recycling activities. Also, redemption of gifts was used to motivate recycling conscious and actions. Individuals living in daily life take critical role of actual participation in the daily environmental protection practices. The excerpt below illustrates the importance of encouragement and reward for reinforcement.

"I am so happy to exchange used paper, glass, food, plastics, electrical appliances, computers, rechargeable batteries, clothes and fluorescent lamps to redeem points for useful household gifts".

\subsection{Caring for Sustainable Development}

The event of "Green Efforts Give Great Rewards Event" has been introduced to encourage residents to adopt a green life. In this scheme, useful household products would be given to residents for any eco-friendly deeds. All life on earth is connected to each other's. The event can spread the knowledge to educate and inspire others. If a company is devoted to run towards sustainability, it should start with the belief that we are part of a larger system of business ecology - and extends the willingness to examine the larger socio-economic system and how we impact it at the individual, community and organizational level, and eventually at the planetary level (Laing \& Frost, 2010). Motivating community to engage voluntarily in pro-environmental behavior at Park Island is expected to contribute to environmental sustainability by reducing greenhouse gas emissions, reducing waste products, increasing recycling, and specifically climate change is perhaps the greatest challenge humanity has ever faced. It is very important and influential to see the management encourages and educates the communities to engage in environmental protection measures daily to ensure sustainable development for future generations. The excerpts below illustrate the importance of sustainable development.

"It is really commendable to see management plan, implement and promote environmental protection events in Park Island. I believe those participants will be inspired to take part to change the world into a better and greener place for you and me!"

"I deeply appreciate the management of Park Island showcases its commitment to environmental protection through educative environmental protection events, to doits utmost to educate residents about green measures, encourage the community to engage in environmentally friendly measures, nurture the environmentally friendly awareness for the next generation".

\subsection{Cutting Carbon Lifestyle}

Management has to lead first. They have to show that they have done everything they can, and then they can ask residents to join the low carbon journey. Low carbon living refers to a lifestyle that emits less carbon dioxide. Some selfish residents just emphasis on convenience or comfort without considering a buy in in a more ecologically favorable and an environmentally friendly fashion in their everyday lives. In this regard, they sacrifice convenience; accept lower levels of performance in eco-friendly products, and even paying extra for the products (Kalafatis et al., 1999, Laroche et al., 2001, Manaktola \& Jauhari, 2007). Residents' pro-environmental responsibility needs to be integrated for the betterment of environmental sustainability of everyday life.Residents must adopt a low carbon lifestyle together for making our island a better place to live. The excerpts below illustrate the creative ways of cutting carbon in their daily life.

"Protecting the environment is not merely an attitude, and daily action is required. Buying products from local farmers not only can guarantee fresh and delicious fruits and food, but also can avoid the usage of fossil fuels during transportation process".

"I live a low-carbon lifestyle that is reasonable for other people in this planet. I am "mainstream green." I commute by public transport. I recycle, reuse and reduce." 


\subsection{Coordinating Effort to Reduce, Reuse, and Recycle}

Household electronic appliances and computers are collected at Environmental protection events to transfer to the charity for the needy. In 2016, the total amount of solid waste disposed of at the strategic landfills was 5.61 million tonnes (Environmental Protection Department, 2016). During the events, stop providing the use of plastic products such as disposable paper cups and straws that take a significant step towards helping to reduce unnecessary consumption. The excerpts below illustrate the significance of reducing, reusing and recycling.

"I bring my reusable water cup, store food in reusable containers, and bring my own recyle and reusable bag when shopping so as to reduce plastics waste".

"Appreciate the management to encourage the community to live green. I have extra books and stationaries; it is a good way to donate them to Salvation Army for re-sending to people in need. I feel morally obligated to engage in reusing."

"I am grateful that some collection points are set to collect used materials for the needy. One of the best things about recycling is that it helps lower costs for society to handle rubbish. We should recycle materials and protect the environment to benefit people."

"We should recycle materials and protect the environment to benefit other people."

Investment was not enough in expanding the manufacturing capacity for recycled products. The recycling industry suffered from financial loss that cannot support recycling operations. The excerpt below points out the shortcomings of the recycling industry in Hong Kong.

"There aren't any papers recycling or manufacturing plants in Hong Kong."

\subsection{Consuming Less Electricity}

Unlike solid waste that has physical and visble image that affect the environment, energy is difficult to quantify and is often taken for granted and regarded as an unavoidable cost (Yu et al., 2012). As buildings account for about $90 \%$ of electricity consumption in Hong Kong, there is great potential to improve energy efficiency and reduce our greenhouse gas emissions by promoting energy efficiency in buildings. All the events were organized in the outdoor area, only sunlight was used. No air-cons and fans were used. The excerpts below illustrate the meanings of using electricity wisely.

"My family and I are deovoted to tackling climate change by changing our behaviour, to make more environmentally responsible decisions, to use more renewables and use energy more wisely so as to reduce our energy related emissions".

\subsection{Concerning Ocean Creatures Protection}

Exhibit boards and booths are set up to educate the community to be aware of the protection of the oceans. Plastics that end up as ocean debris contribute to habitat destruction and entangle and kill lots of marine creatures every year. The excerpts below illustrate the significance of protecting all the ocean creatures.

"I learnt that the oceans are the source of all life on earth that they provide $50 \%$ of the oxygen we breathe, regulate our climate and our rainfall. It reminded me to take responsibility to protect our oceans and all the ocean creatures."

"We should bear in mind that oceans provide seafood, transport and recreational opportunities for human. We should use all those resources in a responsible manner and minimize the negative impacts to ocean creatures".

"We travel the Ocean in a responsible way by choosing the cruise company that concerns about marine conservation".

\subsection{Ceasing Ozone Depleting Chemicals Products}

Although large amount of ozone depleting substances are utilized in commercial and industrial context; community can take part to make a great difference. The suitable way to safeguard the ozone layer is to cut or suspend using ozone depleting products. The excerpts below illustrate the reasons why stop using ozoneharming products are essentials.

"My oblibation to protect the ozone layer is not to purchase those containing ozone depleting products".

"I will buy air-conditioners that do not use HCFCs or CFCs as refrigerants; regularly inspecting and maintaining my air-conditioners and refrigeration appliances to minimize refrigerant leaks". 


\section{Conclusions and Recommendations}

This study is aimed to investigate how a serious of environmental protection events like "Environmental Protection Pioneer Campaign", "Rewarding Recycling Campaign", "Green Efforts Give Great Rewards Event", "Environmental Protection Workshop" and "Environmental Campaign Day", "Environmental Protection Carnival" and "Second-hand Bazaar" contributes to demonstrate environmentally friendly property management and raise the environmental protection awareness and induce greater residents' involvement to live green.

The efforts to combat climate change touch on every part of our lives and should be the responsibilities of all residents, management companies and governments. The issue of climate change can only be sufficiently addressed with wide participation from the governments, different sectors of businesses and residents. The researchers were delighted to learn that educative environmental protection events were perceived by all of the study participants as educative and effective, which demonstrate environmentally friendly property management and raise the environmental protection awareness and encourage residents' involvement to live green. The results of this study appear to suggest that all the residents, estate management companies and governments should actively engage in environmental protection for sustainable development. To achieve this, all residents must contribute by implementing environmentally friendly measures sincerely and seriously such as circulating surplus materials to the needy, choosing public transportation, committing of green education, cultivating pro-environmental behavior, caring for sustainable development, cutting carbon lifestyle, coordinating effort to reduce, reuse, recycle, consuming less electricity, concerning ocean creature's protection and ceasing using ozone depleting chemicals products.

Managerial Implications

The findings of this study have significant implications for estate management. Based on the results of this research, the following are suggestions to induce greater pro-environmental behavior from event attendees.

Recommendations to Estate Management

- Use social media as promotional tools to promote all those events.

- Coordinate with environmental promotion organizations to organize more interactive environmental protection events regularly.

Recommendations to Residents

- Participate in all educative environment events proactively.

- Raise the awareness and willingness to engage in pro-environmental behavior (Schwartz, 1977). Take initiatives to support the recycling practices and share the excess materials to others in need.

Recommendations to Government

- Increasing the scale and spread of sustainable investments by helping the private sector, the financial sector, and investors to understand the benefits of sustainable investment practices in the fields of clean energy, air quality, transportation and others.

- To develop Green Investment Guidelines for the private sectors for ensuring

environmentally-sustainable business practices.

- Government should fully support the recycling industry by subsidizing recycling operations and education on resource recovery and sustainable consumption.

- The Government must also support the local green industry through green procurement, creating a circular economy.

\section{Limitations}

This study has limitations that the authors attribute to the relative weakness of interviews to present valid, reliable and trustworthy empirical evidence. Consequently, it is recognized that the results of this study present a snapshot of thoughts and feelings amongst a specific group of participants about environmental protection events, and at a particular point in time. Even the authors make no claims regarding the generalization of the results, and this study has indicated a concentration of the benefits generated by environmental protection events in Park Island. The research outcome can be beneficial to event organizers to enhance environmental awareness, nurture community's moral obligation to proactive participation in environmentally friendly daily practices, and induce greater pro-environmental behavior for sustainable development. 


\section{References}

Ahmad, N. L., Rashid Wen, N. A., Razak, A. N. M., \& Yusof, N. S. M. (2013). Green Event Management and Initiatives for Sustainable Business Growth. International Journal of Trade, Economics and Finance, 4(5), 331.

Berridge, G. (2007). Events design and experience, Events Management Series (1st ed.). Elsevier. https://doi.org/10.4324/9780080468112

Blewitt, J. (2012). Understanding sustainable development. Routledge. https://doi.org/10.4324/9781849773645

Brandon, P. S., \& Lombardi, P. (2011). Evaluating sustainable development in the built environment. Chichester, West Sussex, Ames, Iowa: Wiley-Blackwell.

Brinsmead, T. S., \& Hooker, C (2011). Complex systems dynamics and sustainability: conception, method and policy (pp. 809-838). In C. Hooker (Ed.), Handbook of the philosophy of science. Amsterdam: North-Holland/Elsevier.

Chan, S. (2012). A study on green housing management: how can housing managers' best leverage green initiatives for sustainable development. Unpublished master thesis, University of Hong Kong, Pokfulam, Hong Kong SAR. https://doi.org/10.5353/th_b4833982

Eckerstein, A. (2002). Evaluation of event marketing. International Management Master Thesis, 25, Goteborg University.

Environment Bureau. (2015). Energy Saving Plan for Hong Kong's Built Environment 2015-2025. Retrieved from https://www.enb.gov.hk/sites/default/files/pdf/EnergySavingPlanEn.pdf

Environmental Protection Department. (2017). Monitoring of Solid Waste in Hong Kong Waste Statistics for 2016. Retrieved from https:/www.wastereduction.gov.hk/sites/default/files/msw2016.pdf

Goldblatt, S. (2011). The Complete Guide to Greener Meetings and Events. Hoboken, New Jersey: John Wiley \& Sons, Inc.

Gordon, W., \& Langmaid, R (1998). Qualitative Market Research: A Practitioner's and Buyer's Guide. Gower, Aldershot.

Green, G. H., \& Haines, A. (2008). Asset building \& community development. Los Angeles: Sage Publications

Holloway I., Brown L., \& Shipway, R. (2007). Meaning not measurement: using ethnography to bring a deeper understanding to the participant experience of festivals and events. International Journal of Event and Festival Management, 1(1), 74-85. https://doi.org/10.1108/17852951011029315

Hove, H. (2004). Critiquing sustainable development: a meaningful way of mediating the development impasse? Undercurrent, 1(1).

Kalafatis, S. P., Pollard, M. R., East, R. R., \& Tsogas, M. H. (1999). Green marketing and Ajzen's theory of planned behaviour: a cross-market examination. Journal of Consumer Marketing, 16(5), 441-460. https://doi.org/10.1108/07363769910289550

Kollmuss, A., \& Agyeman, J. (2002), Mind the gap: Why do people act environmentally and what are the barriers to pro-environmental behavior? Environmental Education Research, 8(3), 239-260.

Laing, J., \& Frost, W (2010). How green was my festival: Exploring challenges and opportunities associated with staging green events. International Journal of Hospitality Management, 29(2), 261-267. https://doi.org/10.1016/j.ijhm.2009.10.009

Lambin, E. F. (2005). Conditions for sustainability of human-environment systems: information, motivation, and capacity. Global Environmental Change, 15(3), 177-180. https://doi.org/10.1016/j.gloenvcha.2005.06.002

Laroche, M., Bergeron, J., \& Barbaro-Forleo, G. (2001). Targeting consumers who are willing to pay more for environmentally friendly products. Journal of Consumer Marketing, 18(6), 503-520. https://doi.org/10.1108/EUM0000000006155

Manaktola, K., \& Jauhari, V. (2007). Exploring consumer attitude and behaviour towards green practices in the lodging industry in India. International Journal of Contemporary Hospitality Management, 19(5), 364-377. https://doi.org/10.1108/09596110710757534

Maser, C., Beaton, R., \& Smith, K. (1998). Setting the Stage for Sustainability. A Citizen's Handbook. Lewis Press. 
Moldan, B. et al. (2012). How to understand and measure environmental sustainability: Indicators and targets. Ecological Indicators, 17, 4-13. https://doi.org/10.1016/j.ecolind.2011.04.033

Prughm, T., \& Assadourian, E. (2003). What is sustainability, anyway? World Watch, 16(5), 10.

Silversm, J. R. (2004). Professional Event Coordination. New Jersey: John Wiley \& Sons Inc.

Slaughter, L., \& Home, R (2004). Motivations of long-term volunteers: human services vs. events, Journal of Hospitality, Tourism and Leisure Science, 2. Retrieved from http:// hotel.unlv.edu/research/htl/articles.html

Smith, K., \& Lockstone, L. (2009). Involving and keeping event volunteers: management insights from cultural festivals. In T. Baum, M. Deery, C. Hanlon, L. Lockstone, \& K. Smith (Eds.), People and Work in Events and Conventions: A Research Perspective (pp. 154-168), CABI, Wallingford, CT. https://doi.org/10.1079/9781845934767.0154

Stern, P. C. (2000). New environmental theories: Toward a coherent theory of environmentally significant behavior. Journal of Social Issues, 56(3), 407-424. https://doi.org/10.1111/0022-4537.00175

Stiglitz, J. E., Sen, A., \& Fitoussi, J. P. (2009). Report by the Commission on the Measurement of Economic Performance and Social Progress.

Swarbrooke, J. (1999). Sustainable tourism management. New York: Cabi. https://doi.org/10.1079/9780851993140.0000

United Nations Secretary and General's High-level Panel. (2012). Global Sustainability. Resilient People, Resilient Planet: A Future Worth Choosing. New York: United Nations.

Veal, A. J. (1994). Research Methods for Leisure and Tourism: A Practical Guide (3rd ed.), Pearson Education, Harlow.

WCED. (1987). World Commission on Environment and Development. Our Common Future. Oxford: Oxford University Press.

Yin, R. K (1994). Case Study Research: Design and Methods (2nd ed.). Thousand Oaks, CA: Sage.

Yu, L., Wang, C., \& Seo, J. (2012). Mega event and destination brand: 2010 Shanghai Expo. International Journal of Event and Festival Management, 3(1), 46-65. https://doi.org/10.1108/17582951211210933

\section{Copyrights}

Copyright for this article is retained by the authors, with first publication rights granted to the journal.

This is an open-access article distributed under the terms and conditions of the Creative Commons Attribution license (http://creativecommons.org/licenses/by/4.0). 